PAPER

\title{
Quality of life and impairment in patients with multiple sclerosis
}

\author{
A-K Isaksson, G Ahlström, L-G Gunnarsson
}

J Neurol Neurosurg Psychiatry 2005;76:64-69. doi: 10.1136/jnnp.2003.029660

See end of article for authors' affiliations

.....................

Correspondence to: A-K Isaksson, Department of Caring Sciences, University of Örebro S-701 82 Örebro,

Sweden;

ann-kristin.isaksson@

ivo.oru.se

Received 21 October 2003

In revised form

7 April 2004

Accepted 9 April 2004
Objectives: The aims of this study were to describe the quality of life in patients with multiple sclerosis (MS) given immunological treatment and in those not given immunological treatment and to investigate the relationship between impairment and quality of life.

Methods: Twenty nine patients given immunological treatment were matched with the same number of patients not given such treatment. Matching variables were sex, Kurtzke's Expanded Disability Status Scale (EDSS), years since diagnosis, and age (total $n=58$ ). The patients were interviewed using the self-reported impairment checklist and they answered two questionnaires on quality of life, the 36-Item Short-Form Health Survey (SF-36) and the Subjective Estimation of Quality of Life (SQoL).

Results: The self-reported impairment checklist captured a more differentiated picture of the patients' symptoms of MS than the EDSS. Health related quality of life was markedly reduced, while the subjective quality of life was less affected. There was a stronger association between self-reported ratings of impairment and health related quality of life on the SF-36 than between impairment and global ratings of quality of life on the SQoL. Subjective quality of life on the SQoL was not directly dependent on impairment expressed in physical limitations. There were no statistically significant differences between the treated and untreated groups. A non-significant trend towards better health related quality of life was found in favour of the treated group with respect to emotional role, physical role, and social function on the SF-36.

Conclusions: The self-reported impairment checklist and SF-36 proved to be valuable complements to the well established EDSS in describing the diverse symptoms of MS. Measuring both health related quality of life and subjective wellbeing provides valuable knowledge about the consequences of MS.
M ultiple sclerosis (MS) is a chronic neurological disease with various neurological symptoms and may lead to severe disability. The onset is primarily within the age range of 20-40 years and it affects women twice as often as men.

Quality of life (QoL) is a subjective and multidimensional concept. Its meaning depends on the theoretical perspective and the context in which it is used. While intending to measure QoL, many researchers are in reality measuring different aspects of health status. ${ }^{1}$ Some instruments focus on current abilities and limitations due to the effects of disease, while others focus on the subjective sense of wellbeing. ${ }^{1-3}$ Studies in patients with MS have shown that wellbeing is not a simple manifestation of impairment or disability. ${ }^{2}$ Health related QoL includes those aspects of QoL which are influenced by the disease.

Patients with MS rate their health related QoL lower than general populations ${ }^{4}$ and also lower than patients with other chronic diseases such as epilepsy and diabetes. ${ }^{6}$ QoL of patients with MS is also influenced by depressive symptoms. ${ }^{7}$ Measurement of QoL of patients with MS is of interest for their medical care, rehabilitation, and nursing.

During the past 10 years several disease modifying parenterally given treatments have been used for MS. The effects of these treatments have been estimated in reference to the number of relapses, the rate of progression, and the change in the magnetic resonance image. Earlier studies on the effect of immunological treatment on QoL were not conclusive: some showed a slight positive effect ${ }^{78}$ while others did not. ${ }^{10}$ Treatment with interferon beta reduces the progression of impairment in patients with MS but brings about adverse effects. Studies have shown that injections of this drug can produce side effects that may have a deleterious effect on QoL irrespective of whether the treatment is given daily or once a week. ${ }^{7}$ The side effects of treatment with interferon beta seem to increase over time. ${ }^{11}{ }^{12}$ Side effects are also reported in patients treated with other parenterally given immunity modifying drugs, such as copolymer- $1^{13}$ and mitoxantrone. ${ }^{14}$

Because of a slower deterioration caused by these treatments we hypothesised that QoL of patients given immunity modifying treatments was better in spite of the side effects. The aim of this study was twofold: to describe QoL of patients with MS on and those not on immunological treatment, and to investigate the relationship between impairment and QoL in these patients.

\section{METHODS \\ Subjects}

The patients were selected from an MS register for the county of Örebro at the Department of Neurology and Clinical Neurophysiology, Örebro University Hospital, Sweden. In the register, all patients were graded by their neurologist according to Kurtzke's Expanded Disability Status Scale (EDSS). ${ }^{15}$ The EDSS gives an estimate of impairment for patients with MS in terms of 20 possible outcomes. The scores are from 0 (= normal neurological status) to 10 (= death from MS). The research ethics committee at Örebro University Hospital gave approval for the project.

In the catchment area of the county of Örebro there were 44 immunologically treated patients in the age range of 1864 years, all having clinically definite and/or laboratory supported definite MS. ${ }^{16}$ A condition for inclusion was that

Abbreviations: EDSS, Expanded Disability Status Scale; MS, multiple sclerosis; QoL, quality of life; SF-36, 36-Item Short-Form Health Survey; SQoL, Subjective Estimation of Quality of Life 
the medical records showed the patients were cognitively able to complete questionnaires. Another condition was that the time since diagnosis should be at least six months to avoid including patients who were in acute crisis and thus emotionally unstable.

To study the subjective experiences of the consequences of MS, the patients were interviewed and given questionnaires to complete. The group size was limited to be able to manage the analysis of qualitative interview data. The results of the interviews will be reported in a future paper. Thus, 31 patients were randomly selected from two age strata, in order to cover all ages. Men and women were stratified to achieve the same distribution of sex as in the whole group of patients, men/women 1:2. Four patients declined to participate and another four of the original 44 replaced these. Out of the participating patients, 20 were being treated with interferon beta-lb, seven with interferon beta-la, three with copolymer- 1 and one with mitoxantrone. The patients had been on treatment for between six months and seven years (mean 2 years; median 1 year).

The 31 treated patients were matched with patients who were not given immunological treatment. The criteria for matching were applied in the following order: sex, impairment (by EDSS), time since diagnosis, age. One of the selected untreated patients moved abroad for a year and could not participate. Another 11 untreated patients were not willing to take part. These patients were replaced with new ones. Two matched pairs were then excluded because one patient ended the treatment without reporting to the physician, while another patient dropped out after the recruitment phase.

Thus the total study group consisted of 29 pairs (58 patients). The median EDSS was 3 in both the treated and the untreated groups. The patients were categorised into three groups according to the EDSS scores: 0-2.5, 3.0-6.0 and $\geqslant 6.5$. ${ }^{4}$ Two thirds of the patients had a relapsing-remitting course (table 1). The mean age of the untreated group was 7 years more than that of the treated group, but no other matching criterion differed significantly between the groups.

Table 1 Demographic and diagnostic characteristics of the two patient groups

\begin{tabular}{|c|c|c|c|}
\hline & All patients & $\begin{array}{l}\text { Treated } \\
\text { patients }\end{array}$ & $\begin{array}{l}\text { Untreated } \\
\text { patients }\end{array}$ \\
\hline No. & 58 & 29 & 29 \\
\hline \multicolumn{4}{|l|}{ Sex, n (\%) } \\
\hline Women & $38(65.5)$ & $19(66)$ & $19(66)$ \\
\hline Men & 20 (34.5) & $10(34)$ & $10(34)$ \\
\hline \multicolumn{4}{|l|}{ Age in years } \\
\hline Mean (SD) & $42(10.6)$ & $38.6(9.4)$ & $45.5(10.7)$ \\
\hline Range & $20-70$ & $20-55$ & $25-70$ \\
\hline \multicolumn{4}{|l|}{ Disease pattern, n (\%) } \\
\hline Relapsing-remitting MS & $37(64)$ & $17(59)$ & $20(69)$ \\
\hline Secondary progressive MS & $15(26)$ & $11(38)$ & $4(14)$ \\
\hline Primary progressive MS & $6(10)$ & $1(3)$ & $5(17)$ \\
\hline \multicolumn{4}{|l|}{ Years since diagnosis } \\
\hline Mean (SD) & $4.88(3.4)$ & $4.97(3.7)$ & $4.79(3.1)$ \\
\hline Range & $1-15$ & $1-15$ & $1-11$ \\
\hline \multicolumn{4}{|l|}{ EDSS score, $\mathrm{n}(\%)$} \\
\hline $0.0-2.5$ & $26(45)$ & $12(41)$ & $14(48)$ \\
\hline $3.0-6.0$ & $28(48)$ & $15(51)$ & $13(45)$ \\
\hline$\geqslant 6.5^{*}$ & $4(7)$ & $2(7)$ & $2(7)$ \\
\hline \multicolumn{4}{|l|}{ Civil status, $n(\%)$} \\
\hline Living alone & $23(40)$ & $12(41)$ & $11(38)$ \\
\hline $\begin{array}{l}\text { Married/cohabiting } \\
\text { partner }\end{array}$ & $35(60)$ & $17(59)$ & $18(62)$ \\
\hline
\end{tabular}

\section{Instruments}

\section{Self-reported impairment}

When interviewing the patients a checklist for screening 15 signs of impairment ${ }^{17}$ was used (table 2). The patients were asked if they had symptoms of impairment, if the symptoms were moderate or severe, and if the symptoms were constant or fluctuating. This self-reported impairment checklist was constructed for stroke patients ${ }^{18}$ and has proved to be informative regarding several aspects of neurological deficits. In the present study it was modified for MS symptoms on the basis of literature research ${ }^{19}$ and clinical experience.

To capture both health related QoL and subjective wellbeing two instruments were used for data collection on QoL.

The 36 item short-form health survey (SF-36)

The SF-36 is a self-assessment instrument for health related QoL. ${ }^{2021}$ It has been shown to capture the broad effects of health problems of patients with $\mathrm{MS}^{4}{ }^{4}$ This instrument groups 35 items into eight scales: physical function, physical role limitation, bodily pain, general health, vitality, social function, emotional role limitations, and mental health. The items were coded and transformed into a scale from 0 to 100 following the standard in the SF-36 manual. Lower scores reflect lower health related QoL. ${ }^{22}{ }^{23}$ A further single item, "health change", which concerns the past year, was rated on the Likert scale (1-5).

The instrument is widely used and has been well validated in several studies. $^{3421}$ It has been translated and has undergone psychometric testing with satisfying results of use in many countries, including Sweden. ${ }^{21}$ Intercorrelation of the SF-36 dimensions showed that each dimension was measuring a related but distinct construction. ${ }^{3}$ In this study the Swedish version of the SF-36 was used and reliability for the eight dimensions and all items was high, with Cronbach's $\alpha$ ranging between 0.74 and 0.93 .

The subjective estimation of quality of life (SQoL) This instrument reflects subjective QoL from an interactionistic perspective including social, psychological, and interpersonal aspects of wellbeing. ${ }^{24}{ }^{25}$ The SQoL is intended both for healthy persons and for different patient groups. The instrument has three socioeconomic variables, five about relations, nine about personal feelings and one about QoL as a whole (see table 4 later). The respondent evaluates the degree of satisfaction in his or her current life situation for each of these 18 variables. There is a Likert scale (1-5) for the answers, including half-steps. A lower score reflects lower subjective QoL. Each variable is represented by one item, except three variables, which have two items that are mutually exclusive. For example, if the person has rated the quality of relationship to his or her partner, they do not go on to the next item, since that involves rating the situation of having no partner.

The SQoL has been used in previous studies and has been shown to have acceptable validity. ${ }^{24} 26$ Cronbach's $\alpha$ in this study was 0.90 for all items. Since only one patient answered the item "have no friends" this item was excluded from the presentation of the results.

\section{Procedure}

The patients were sent a letter with information about the study. Three to five days later the researcher phoned, gave more information and asked if they were willing to participate.

The data were collected on two occasions for this study. On the first occasion, the patients were interviewed individually by A-KI with the structured guide of the self-reported impairment checklist instrument. They were given the SF36 as a mail questionnaire to be completed within two weeks. The second data collection was roughly four months later when the SQoL questionnaire was answered. 


\begin{tabular}{|c|c|c|c|c|c|}
\hline \multirow{2}{*}{$\begin{array}{l}\text { Multiple sclerosis: } \\
\text { symptoms/impairment }\end{array}$} & \multicolumn{3}{|l|}{ Problem } & \multicolumn{2}{|c|}{ Duration of problem } \\
\hline & None (n) & Moderate (n) & Severe (n) & Fluctuating (n) & Constant (n) \\
\hline Balance/vertigo & 10 & 37 & 11 & 9 & 39 \\
\hline Walking & 11 & 27 & 20 & 7 & 40 \\
\hline Hand/finger & 30 & 19 & 9 & 5 & 23 \\
\hline Sensory dysfunction & 27 & 21 & 10 & 5 & 26 \\
\hline Spasticity & 25 & 25 & 8 & 5 & 28 \\
\hline Coordination & 44 & 10 & 4 & 1 & 13 \\
\hline Pain & 31 & 18 & 9 & 11 & 16 \\
\hline Fatigue & 13 & 20 & 25 & 3 & 42 \\
\hline Speech & 47 & 9 & 2 & 2 & 9 \\
\hline Bladder function & 19 & 22 & 17 & 3 & 36 \\
\hline Eyesight problem & 39 & 15 & 4 & 7 & 12 \\
\hline Sexual function & 34 & 16 & 8 & 2 & 22 \\
\hline Concentration/poor memory & 39 & 17 & 2 & 2 & 17 \\
\hline Heat sensitivity & 31 & 17 & 10 & 0 & 27 \\
\hline Paroxysmal symptoms* & 45 & 12 & 0 & 9 & 3 \\
\hline
\end{tabular}

\section{Statistics}

Wilcoxon's matched pair rank sum test was used to compare the two groups. Spearman's non-parametric correlation $\left(\mathrm{r}_{\mathrm{s}}\right)$ was used to investigate the relationship between impairment and quality of life. The interpretation of significant correlation was as follows: little or none $(\leqslant 0.25)$, fair $(0.25-0.50)$, moderate to good $(0.50-0.75)$, and excellent $(\geqslant 0.75) .^{28}$ Interpretation of statistically significant results was done at the $\mathrm{p}<0.05$ level.

From the study group of 29 pairs one patient did not answer the SF-36, so one matched pair was dropped out of the matched analyses-that is, 28 pairs were accounted for in the SF-36 results. There were two changes of treatment during the period of data collection. One patient started treatment and one ended treatment, reducing the matched pairs for comparison between the groups to 27 for the SQoL results.

\section{RESULTS}

Table 2 indicates that the most frequent signs of impairment for the whole group were disturbed balance and problems in walking. Both symptoms affected $80 \%$ of the patients and were reported to be constant in four out of five patients. Fatigue and bladder dysfunction were also constant symptoms in four out of five patients. Heat sensitivity was reported by every other patient and it was a constant problem for all of them. They reacted to higher temperatures such as fever or the summer heat and for some a few degrees higher indoor temperature could make them very weak or tired.

The two patient groups were quite similar with regard to the impairment checklist. The main difference was found in sensory dysfunction, which was reported by $62 \%$ (18/29) of the treated and $45 \%(13 / 29)$ of the untreated patients. Pain was also more frequently reported by the treated patients than by the untreated patients (55\% (16/29) and 38\% (11/29), respectively). However, when comparing the two groups there was no statistically significant difference between the medians.

In the whole group of patients, MS had the most negative influence on health related QoL in the SF-36 questionnaire concerning vitality, general health, physical role, and physical function. On comparing treated and untreated patients, there were no statistically significant differences between the groups. However, a trend towards lower health related QoL was found in the untreated group in respect of emotional role (difference of medians, 33), physical role limitation (25) and social function (18) (table 3). For the other variables less variation was found in both directions, with the difference between the medians of the two groups in the range of 5-10. For the item concerning health change during the past year both the treated and untreated group reported that their health was about the same.

With the SQoL the patients rated their self-satisfaction with regard to social features, relations, and subjective feelings (table 4). The highest satisfaction for all patients was in regard to relation to own children (median 5.0), followed by housing quality, relations with friends, and emotional experience (all 4.5). The most negative influence on subjective QoL was their experience of have no meaningful work, having no partner, having no children, and energy (all 3.0). The distributions of the answers were skewed. There were no statistically significant differences between the medians of the two groups.

In order to check for influences of negative and positive events in the time between the two data collections, the analysis was reiterated after excluding first, the patients with negative experiences $(n=4)$, and then, the patients with positive experiences $(n=8)$. The results showed the same patterns, with no significant differences in the analysis of the SQoL between the treated and the untreated groups.

The comparison of the two impairment scales showed the most marked correlation was between the EDSS and walking in the self-reported impairment checklist $\left(\mathrm{r}_{\mathrm{s}}=0.62, \mathrm{p}<0.01\right)$. Statistically significant correlations also emerged for balance/ vertigo $\left(r_{\mathrm{s}}=0.44\right)$, heat sensitivity $\left(\mathrm{r}_{\mathrm{s}}=0.38\right)$, and spasticity $\left(\mathrm{r}_{\mathrm{s}}=0.35\right)$.

There was a statistically significant correlation between impairment estimated by EDSS and six variables of the SF36. As expected, the most evident association was with physical function $\left(r_{s}=0.62\right)$. Bodily pain, general health, social function, physical role limitation, and emotional role limitation also correlated $\left(r_{s}=0.28-35\right)$. Little or no correlation was found between the EDSS and SQoL.

Pain and problems with walking on the self-reported impairment checklist had the highest correlation with health related QoL estimated with the SF-36 (table 5). Most of the problems concerning physical function had to do with walking, spasticity, and balance/vertigo. The physical role limitations were mainly associated with problems to do with walking, fatigue, and concentration/poor memory. As expected, there was excellent agreement between SF-36 bodily pain and reported pain. The impairments pain, fatigue and concentration/poor memory had the highest impact on vitality, social function, and mental health. 
Table 3 Health related quality of life in patients with multiple sclerosis

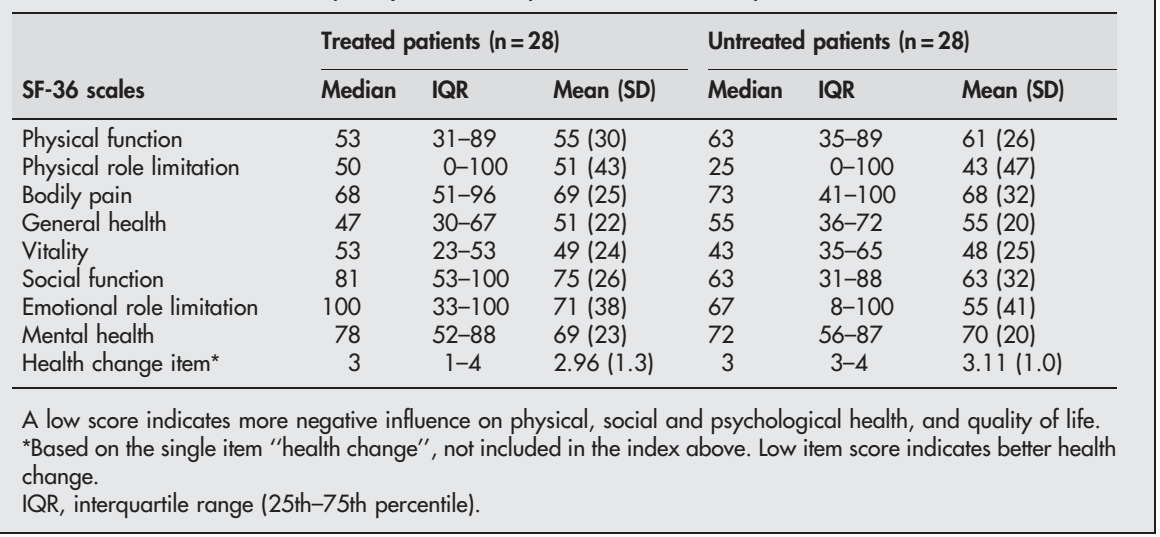

Concerning correlation between self-reported impairment and the SQoL, the impairment concentration/poor memory was moderately correlated with having no work $\left(\mathrm{r}_{\mathrm{s}}=-0.63\right.$, $p<0.05)$, energy $\left(r_{s}=-0.49, p<0.01\right)$, and self-assuredness $\left(\mathrm{r}_{\mathrm{s}}=-0.47, \mathrm{p}<0.01\right)$. Also, a moderate correlation emerged for fatigue and having no work $\left(\mathrm{r}_{\mathrm{s}}=-0.57, \mathrm{p}<0.05\right)$.

The results showed that both EDSS and self-reported impairment had a stronger association with health related quality of life on the SF-36 than with the subjective global ratings of quality of life on the SQoL.

\section{DISCUSSION}

This study aimed to describe the QoL in patients with MS receiving parenteral immunological treatment and in a similar untreated group of patients. No statistically significant differences were found between the groups with regard to their subjective and health related QoL. The largest absolute differences found might indicate that the treated group had a better health related QoL with regard to social function and experienced less limitation of emotional and physical roles. This difference could be explained by the fact that the treatment of the patients was initiated prior to the start of the study and might have contributed to a selection bias concerning activity of disease-that is, the patients' desire to be treated and doctors' willingness to initiate immunological treatments. In another study that also included patients treated prior to the start of the study at the one year follow up the QoL was unchanged although the side effects of treatment increased over time. ${ }^{11}$ Review papers on immunological treatment published in recent years in which QoL was used as an outcome variable concluded that treatment is also associated with a slower deterioration of health related QoL ${ }^{2}$ but that further research is needed, including randomised trials. ${ }^{29}$

Immunological treatment (interferon and copolymer) is administered by self-injection once a week or every day depending on the type of substance. The exception is mitoxantrone, which is given only every third month. Patients can get skin reactions at injection sites and other side effects. ${ }^{30}$ In all cases the treatments can obviously give rise to restrictions in everyday life, and repeatedly make the patients aware of their chronic disease. On the other hand, there are benefits such as an expected reduction of disease activity and constant access to health care in conjunction with treatment and follow up. This may explain the tendency towards a higher health related QoL assessed by the SF-36 in

Table 4 Subjective estimation of quality of life in patients with multiple sclerosis

\begin{tabular}{|c|c|c|c|c|c|c|}
\hline \multirow[b]{2}{*}{ Variables/items } & \multicolumn{3}{|c|}{ Treated patients $(n=27$ ) } & \multicolumn{3}{|c|}{ Untreated patients $(n=27)$} \\
\hline & $\mathbf{n}$ & Median & IQR & $\mathbf{n}$ & Median & IQR \\
\hline 1. Housing quality & 27 & 4.5 & $4.0-5.0$ & 27 & 5.0 & $4.0-5.0$ \\
\hline 2.a. Have work, meaningful occupation & 19 & 4.0 & $3.0-4.0$ & 20 & 4.0 & $3.5-5.0$ \\
\hline b. Have no work, meaningful occupation & 8 & 2.5 & $1.0-3.8$ & 7 & 3.0 & $2.0-4.0$ \\
\hline $\begin{array}{l}\text { 3. Quality of personal economy } \\
\text { 4. Relationship to partner }\end{array}$ & $26^{*}$ & 4.0 & $3.0-4.0$ & 27 & 4.0 & $3.0-5.0$ \\
\hline a. Have a partner & 17 & 4.5 & $3.8-5.0$ & 18 & 4.0 & $4.0-5.0$ \\
\hline b. Have no partner & 10 & 3.0 & $2.8-3.3$ & 9 & 2.0 & $1.5-3.0$ \\
\hline 5. Relationship to friends & $26^{*}$ & 4.0 & $3.5-5.0$ & 27 & 4.5 & $3.5-5.0$ \\
\hline 6. Relationship to mother & 27 & 5.0 & $4.0-5.0$ & 27 & 4.0 & $3.5-5.0$ \\
\hline 7. Relationship to father & $26^{*}$ & 4.0 & $2.8-5.0$ & 27 & 4.0 & $4.0-5.0$ \\
\hline 8.a. Relationship to own children & 15 & 4.5 & $4.0-5.0$ & 21 & 5.0 & $4.5-5.0$ \\
\hline b. Have no children & 12 & 3.0 & $3.0-5.0$ & 6 & 3.0 & $2.0-4.3$ \\
\hline 9. Involvement & 27 & 4.0 & $3.0-5.0$ & 27 & 4.0 & $3.5-4.5$ \\
\hline 10. Energy & 27 & 3.0 & $2.0-4.0$ & 27 & 3.5 & $3.0-4.0$ \\
\hline 11. Self-actualisation & 27 & 3.0 & $3.0-4.0$ & 27 & 4.0 & $3.0-4.0$ \\
\hline 12. Freedom & 27 & 3.5 & $2.0-4.0$ & 27 & 4.0 & $3.0-4.5$ \\
\hline 13. Self-assuredness & 27 & 3.5 & $3.0-4.0$ & 27 & 4.0 & $3.5-4.0$ \\
\hline 14. Self-acceptance & 27 & 4.0 & $3.0-4.5$ & 27 & 4.0 & $3.5-4.5$ \\
\hline 15. Emotional experiences & 27 & 4.5 & $3.5-5.0$ & 27 & 4.5 & $4.0-4.5$ \\
\hline 16. Security & 27 & 4.0 & $3.0-4.0$ & 27 & 4.0 & $3.0-4.5$ \\
\hline 17. General mood & 27 & 4.0 & $3.0-4.5$ & 27 & 4.0 & $3.5-4.5$ \\
\hline 18. Quality of life as a whole & 27 & 4.0 & $3.0-4.5$ & 27 & 4.0 & $3.5-4.5$ \\
\hline
\end{tabular}

A low score indicates more negative influence on the subjective quality of life. *One missing.

$I Q R$, interquartile range (25th-75th percentile). 
Table 5 Correlations between self-reported impairment and the eight dimensions of the SF-36

\begin{tabular}{|c|c|c|c|c|c|c|c|c|}
\hline \multirow[b]{2}{*}{$\begin{array}{l}\text { Multiple sclerosis } \\
\text { symptoms/ impairment }\end{array}$} & \multicolumn{8}{|c|}{ Spearman's rank correlation coefficient $\left(r_{s}\right)$} \\
\hline & $\begin{array}{l}\text { Physical } \\
\text { function }\end{array}$ & $\begin{array}{l}\text { Physical role } \\
\text { limitation }\end{array}$ & Bodily pain & $\begin{array}{l}\text { General } \\
\text { health }\end{array}$ & Vitality & $\begin{array}{l}\text { Social } \\
\text { function }\end{array}$ & $\begin{array}{l}\text { Emotional role } \\
\text { limitation }\end{array}$ & Mental health \\
\hline $\begin{array}{l}\text { Balance/vertigo } \\
\text { Walking } \\
\text { Hand/finger } \\
\text { Sensory function } \\
\text { Spasticity } \\
\text { Coordination } \\
\text { Pain } \\
\text { Fatigue } \\
\text { Speech } \\
\text { Bladder function } \\
\text { Eyesight } \\
\text { Sexual function } \\
\text { Concentration/poor memory } \\
\text { Heat sensitivity } \\
\text { Paroxysmal }\end{array}$ & $\begin{array}{l}-0.49^{* *} \\
-0.71^{\star *} \\
-0.52^{\star *} \\
-0.34^{*} \\
-0.33^{*} \\
-0.28^{*}\end{array}$ & $\begin{array}{l}-0.41^{* *} \\
-0.39^{* *} \\
-0.32^{*} \\
-0.36^{* *} \\
-0.43^{* *} \\
-0.31^{*} \\
-0.49^{* *}\end{array}$ & $\begin{array}{l}-0.42^{* *} \\
-0.30^{*} \\
-0.78^{* *} \\
-0.33^{*} \\
-0.32^{*} \\
-0.38^{* *} \\
-0.45^{* *}\end{array}$ & $\begin{array}{l}-0.27^{*} \\
-0.37^{* *} \\
-0.31^{*}\end{array}$ & $\begin{array}{l}-0.30^{*} \\
-0.34^{*} \\
-0.40^{* *} \\
-0.54^{* *} \\
-0.52^{\star *} \\
-0.28^{*} \\
-0.43^{\star *} \\
-0.30^{*} \\
-0.28^{*} \\
-0.53^{* *}\end{array}$ & $\begin{array}{l}-0.35^{\star *} \\
-0.31^{*} \\
-0.41^{\star *} \\
-0.46^{* *} \\
-0.48^{\star *} \\
-0.37^{* *} \\
-0.27^{*} \\
-0.47^{* *}\end{array}$ & $\begin{array}{l}-0.28^{*} \\
-0.44^{* *} \\
-0.36^{* *} \\
-0.43^{* *}\end{array}$ & $\begin{array}{l}-0.28^{*} \\
-0.38^{* *} \\
-0.32^{*} \\
-0.48^{* *} \\
-0.41^{* *} \\
-0.28^{*} \\
-0.34^{*} \\
-0.35^{\star *}\end{array}$ \\
\hline
\end{tabular}

the treated group with respect to social function, emotional role limitation, and physical role limitation. Confidence intervals (CI) for $95 \%$ of the median differences were calculated ${ }^{31}$ and confirmed the tendency found. The lack of significance might have been influenced by the study size of only 58 patients. A larger study sample would have given narrower $\mathrm{CI}$, thus rejecting or confirming the present findings.

The study showed that the two measures of impairment, the EDSS and the self-reported impairment checklist, correlated with regard to mobility factors. The EDSS mainly focuses on the ability to walk and move and the self-reported impairment checklist seemed to be a good complement to it. In spite of the fact that only four of the patients had an EDSS score over six and were users of a wheelchair, the checklist gave a much more differentiated picture of the patients' problems. The patients were also asked if they had any other symptoms of MS besides those predetermined on the selfreported checklist, and two patients added problems with the bowel. Earlier research concerning MS showed bowel impairment in $12 \%$ of the patients. ${ }^{5}$ Thus questions on bowel problems should be added to the instrument for better investigation of the multiplicity of MS symptoms. The selfreported checklist was easy to comprehend and reply to for the patients. A limitation was that it has not been validated on patients with MS.

Concerning health related QoL on the SF-36 the study group reported lower scores than the general Swedish population. ${ }^{32}$ The SF-36 has been used in several previous studies with patients with MS and has shown floor effects for patients with severe disease. ${ }^{3}$ This was not the case in the present study, although the patients had low to moderate EDSS scores. There are several generic instruments for evaluating health related QoL, and SF-36 is a reasonable choice for patients with MS. ${ }^{3933}$ The advantage of using a generic health related scale is the possibility of comparison between different chronically ill patient groups but the disadvantage is the risk of ignoring specific areas of function of MS. One possibility is to combine a generic and an MS specific subscale. ${ }^{29} 34$

Although the patient groups were matched to be as similar as possible regarding sex, EDSS, time since diagnosis, and age, the average age of the treatment group was seven years less. Age can be a factor of bias in measuring health related QoL. The older the person, the lower the health related QoL was shown in a population based study for the SF-36. ${ }^{22}$ The tendency towards higher health related QoL in the treated group might be explained by the fact that they were on average seven years younger than the untreated. To test this all the patients were dichotomised into a younger group (2044) and an older group (45-70). The test revealed that the older group had statistically significant lower health related QoL estimated by SF-36 with regard to physical function, bodily pain, vitality, and social function (Mann-Whitney test: all $\mathrm{p}<0.05$ ).

The reason for combining the SF-36 and the SQoL was to get one instrument for health related QoL and another instrument which did not involve physical function but captured both a subjective and an interactionistic perspective on wellbeing. ${ }^{25}$ The results verified that the health related QoL (SF-36) was related to both measures of impairment, while the subjective wellbeing assessed by the SQoL seemed to be quite independent of impairment. Other studies on progressive muscular dystrophies have shown a relative independence between physical and psychosocial dimensions of QoL. ${ }^{35}{ }^{36}$ The association between health status and wellbeing is not straightforward because the latter may reflect adjustment to disease. Patients with longer duration of disease and who are older are more likely to report a relatively good subjective QoL. ${ }^{5}$ Cognitive theories of stress emphasise the role of appraisal and interpretation in the process of coping with stressful situations. ${ }^{37}$ Our study supports these findings except for the impairment problems concerning concentration and poor memory, which were related to subjective QoL in the aspects of have no work, energy, and self-assuredness. Also, fatigue reduced wellbeing for the patients in relation to work.

Even in health related QoL different scales can be affected by adjustment. Previous research with the SF-36 has shown that patients with severe physical function limitations remain stable on the mental health scale, which may indicate a strong psychological adjustment process for that scale. ${ }^{38}$ Several research studies have been done with numerous instruments for health related QoL for patients with MS and the SF-36 has a dominant role. ${ }^{29}$ However, further research on health related and subjective wellbeing in relation to QoL is needed to clarify all the dimensions of QoL for patients with MS.

The present study has addressed the wide spectrum of symptoms in patients with MS. Both the presented checklist (self-reported impairment) and health related QoL (SF-36) could be valuable complements to the well-established EDSS to describe the diverse symptoms of MS. The subjective 
wellbeing reflects other aspects of life, which could help healthcare professionals in providing support and good health care for those patients living with MS. Important to note is that the SQoL was not directly dependent on impairment expressed in physical limitations.

Since this study is a part of a larger investigation, we hope that forthcoming reports including qualitative interview data will give a more comprehensive picture of the consequences of MS for the patients.

\section{Authors' affiliations}

A-K Isaksson, G Ahlström, Department of Caring Sciences, Örebro University, Sweden

L-G Gunnarsson, Department of Neurology and Movement Disorders, University of Linköping, Sweden

This study was supported by grants from the Centre for Rehabilitation Research, Örebro County Council, the Research Committee of Örebro University Hospital, the Swedish Association of the Neurologically Disabled (the NHR Foundation) and the Department of Caring Sciences, University of Örebro.

Competing interests: A-KI has been reimbursed for attending several symposiums as a clinical MS-nurse before starting research-for example, RIMS (Rehabilitation in MS) conference. Attendance was for educational purposes for clinical practice and did not involve any presentation. Schering Nordic Inc. (Betaferon) has reimbursed five international conferences and three or four national, Serono (Rebif) one international, and Biogen (Avonex) one national.

\section{REFERENCES}

1 Gill T, Feinstein A. A critical appraisal of the quality of quality-of-life measurements. JAMA 1994;24/31:619-26.

2 Benito-Leon J, Morales JM, Rivera-Navarro J, et al. A review about the impact of multiple sclerosis on health-related quality of life. Disabil Rehabil 2003;25:1291-303

3 Freeman J, Hobart J, Langdon D, et al. Clinical appropriateness: a key factor in outcome measure selection: the 36 item short form health survey in multiple sclerosis. J Neurol Neurosurg Psychiatry 2000;68:150-6.

4 Nortvedt M, Riise T, Myhr K, et al. Quality of life in multiple sclerosis: measuring the disease effects more. Neurology 1999;53:1098-103.

5 Ford H, Gerry E, Johnson M, et al. Health status and quality of life of people with multiple sclerosis. Disabil Rehabil 2001;23:516-21.

6 Hermann B, Vickrey B, Hays R, et al. A comparison of health-related quality of life in patients with epilepsy, diabetes and multiple sclerosis. Epilepsy Res 1996;25:113-18.

7 Arnoldus JH, Killestein J, Pfennings LE, et al. Quality of life during the first 6 months of interferon-beta treatment in patients with MS. Mult Scler 2000;6:338-42.

8 Freeman JA, Hobart JC, Langdon DW, et al. Clinical appropriateness: a key factor in outcome measure selection: the 36 item short form health survey in multiple sclerosis. J Neurol Neurosurg Psychiatry 2000;68:150-6.

9 Nortvedt MW, Riise T, Myhr KM, et al. Type I interferons and the quality of life of multiple sclerosis patients. Results from a clinical trial on interferon alfa-2a. Mult Scler 1999;5:317-22.

10 Schwartz CE, Coulthard-Morris L, Cole B, et al. The quality-of-life effects of interferon beta-1b in multiple sclerosis. An extended Q-TWiST analysis. Arch Neurol 1997;54:1475-80.

11 Zivadinov R, Zorzon M, Tommasi MA, et al. A longitudinal study of quality of life and side effects in patients with multiple sclerosis treated with interferon beta-1a. J Neurol Sci 2003;216:113-18.
12 Freeman JA, Thompson AJ, Fitzpatrick R, et al. Interferon-betalb in the treatment of secondary progressive MS: impact on quality of life. Neurology 2001;57:1870-5

13 Dhib-Jalbut S. Glatiramer acetate (Copaxone) therapy for multiple sclerosis. Pharmacol Ther 2003;98:245-55.

14 Myers LW. Immunologic therapy for secondary and primary progressive multiple sclerosis. Curr Neurol Neurosci Rep 2001;1:286-93.

15 Kurtzke J. Rating neurologic impairment in multiple sclerosis: An expanded disability status scale (EDSS). Neurology 1983;33:1444-52.

16 Poser CM, Paty DW, Scheinberg L, et al. New diagnostic criteria for multiple sclerosis: guidelines for research protocols. Ann Neurol 1983;13:227-31.

17 World Health Organization. International classification of function, disability and health (ICF). www.who/.int/icidh/01 1031 (accessed 25 May 2004).

18 Widar M, Ahlström G. Disability after stroke and the influence of long term pain on everyday life. Scand J Caring Sci 2002;16:302-10.

19 Olek M, Dawson D. Multiple sclerosis and other inflammatory demyelinating diseases of the central nervous system. In: Marsden C, ed. Neurology in Clinical Practice. Butterworth-Heinemann, 2000:1431-63.

20 Ware JJ, Sherbourne C. The MOS 36-Item Short-Form Health Survey (SF-36). Med Care 1992:30:473-83.

21 Sullivan M, Karlsson J, Ware EJ. The Swedish SF-36 Health Survey-I. Evaluation of data quality, scaling assumptions, reliability and construct validity across general populations in Sweden. Soc Sci Med 1995:41:1349-58

22 Sullivan M, Karlsson J, Ware JJ. SF-36 Hälsoenkät: Svensk Manual och Tolkningsguide (Swedish manual and interpretation guide). Göteborg: Sahlgrenska University Hospital, 1994.

23 Sullivan M, Karlsson J. The Swedish SF-36 Health Survey III. Evaluation of criterion- based validity: results from normative population. J Clin Epidemiol 1998;51:1105-13.

24 Kajandi M. Psychiatric and interactional perspective on quality of life. In: Nordenfeldt $\mathrm{L}$, ed. Concepts and measurement of quality of life in health care. Dordrecht: Kluwer Academic, 1994:257-77.

25 Naess S. Quality of life research. Concepts, Methods, and Applications. Oslo: Institute of Applied Social Research, 1987.

26 Hugosson S, Carlsson E, Borg E, et al. Audiovestibular and neuropsychological outcome of adults who had recovered from childhood bacterial meningitis. Int J Pediatr Otorhinolaryngol 1997;42:149-67.

27 Bergemalm PO, Borg E. Long-term objective and subjective audiologic consequences of closed head injury. Acta Otolaryngol 2001;121:724-34.

28 Colton T. Statistics in medicine. Boston: Little, Brown, 1974.

29 Nortvedt MW, Riise T. The use of quality of life measures in multiple sclerosis research. Mult Scler 2003;9:63-72.

30 Hickey J. Multiple sclerosis. In: Hickey J, ed. The Clinical Practice of Neurological and Neurosurgical Nursing. Philadelphia: Lippincott, 1997.

31 Altman D. Practical statistics for medical research. London: Chapman \& Hall, 1991.

32 Sullivan M, Karlsson J. The Swedish SF-36 Health Survey III. Evaluation of criterion-based validity: results from normative population. J Clin Epidemiol 1998;51:1105-13.

33 Nortvedt M, Riise T, Myhr K, et al. Quality of life as a predictor for change in disability in MS. Neurology 2000;55:51-4.

34 Schwartz CE, Vollmer T, Lee H. Reliability and validity of two self-report measures of impairment and disability for MS. North American Research Consortium on Multiple Sclerosis Outcomes Study Group. Neurology 1999;52:63-70.

35 Ahlström G, Gunnarsson L-G, Kihlgren A, et al. Respiratory function, electrocardiography and quality of life in individuals with muscular dystrophy. Chest 1994; 106:173-9.

36 Ahlström G. Consequences of muscular dystrophy: Impairment, disability, coping and quality of life. (Dissertation) Acta Universitatis Uppsaliensis, 489 Uppsala, Sweden: Uppsala University, 1994

37 Lazarus R, Folkman S. Stress, appraisal, and coping. New York: Springer, 1984.

38 Singer M, Hopman W, MacKenzie T. Physical function and mental health in patients with chronic medical conditions. Qual Life Res 1999;8:687-91. 